\title{
Projection of Future Hydropower Generation in Samanalawewa Power Plant, Sri Lanka
}

\author{
Bhabishya Khaniya (D), Chamaka Karunanayake (D), Miyuru B. Gunathilake (iD, \\ and Upaka Rathnayake \\ Department of Civil Engineering, Faculty of Engineering, Sri Lanka Institute of Information Technology, Malabe, Sri Lanka \\ Correspondence should be addressed to Upaka Rathnayake; upakasanjeewa@gmail.com
}

Received 3 September 2020; Revised 6 October 2020; Accepted 8 October 2020; Published 17 October 2020

Academic Editor: Danial Armaghani

Copyright ( $\odot 2020$ Bhabishya Khaniya et al. This is an open access article distributed under the Creative Commons Attribution License, which permits unrestricted use, distribution, and reproduction in any medium, provided the original work is properly cited.

\begin{abstract}
The projection of future hydropower generation is extremely important for the sustainable development of any country, which utilizes hydropower as one of the major sources of energy to plan the country's power management system. Hydropower generation, on the other hand, is mostly dependent on the weather and climate dynamics of the local area. In this paper, we aim to study the impact of climate change on the future performance of the Samanalawewa hydropower plant located in Sri Lanka using artificial neural networks (ANNs). ANNs are one of the most effective machine learning tools for examining nonlinear relationships between the variables to understand complex hydrological processes. Validated ANN model is used to project the future power generation from 2020 to 2050 using future projected rainfall data extracted from regional climate models. Results showcased that the forecasted hydropower would increase in significant percentages $(7.29 \%$ and $10.22 \%)$ for the two tested climatic scenarios (RCP4.5 and RCP8.5). Therefore, this analysis showcases the capability of ANN in projecting nonstationary patterns of power generation from hydropower plants. The projected results are of utmost importance to stakeholders to manage reservoir operations while maximizing the productivity of the impounded water and thus, maximizing economic growth as well as social benefits.
\end{abstract}

\section{Introduction}

Hydropower spines almost $16 \%$ of the total electricity generation, which is far more than the contribution from any other renewable resources all over the world [1]. Hydropower plants supply as much as $40 \%$ of the energy required to satisfy Sri Lanka's power demand [2]. Harnessing electricity from hydropower is still considered one of the most sustainable methods of power generation around the world. Therefore, a $75-100 \%$ upsurge in production capacity is expected in the near future [1]. Developing countries have just explored $23 \%$ of its economically feasible hydropower projects relative to developed countries, which have exploited $70 \%$ of their potential [3]. Many developing countries are now rapidly investing significant capital in developing hydropower plants as it is regarded to be a secure and affordable form of sustainable energy, limiting carbon emissions [4]. However, the output from the hydropower plant is highly variable as the production largely depends on climatic factors and weather conditions. Apart from this, global warming is likely to alter water cycle phenomena, frequency of rainfall events, and temperature rise causing disruptions to smooth operation of hydropower plants. For example, the temperature in Sri Lanka is increasing at the rate of $0.0164^{\circ} \mathrm{C} /$ year, influencing intensifications in evaporation [5]. Even though the seasonal rainfall is expected to increase in the coastal areas, rainfall patterns in mountainous areas of Sri Lanka, where most of the hydropower plants are located, are very dynamic and rapidly fluctuating [6].

The hydropower industry stands a high chance to get splintered into the most vulnerable industry if confronted by detrimental impacts of climate change either due to the unavailability of water in the basin area for a long period of 
time or due to excess water resulting in landslide or soil erosion in the catchment area. On the other hand, developing hydropower systems is very costly and causes significant threats to aquatic ecosystem preservation and social concerns [7]. Therefore, forecasting energy production from hydropower plants is crucial, not only to optimize the demand of renewable energy needed for growing demand but also to manage the operations within the hydropower plant (e.g., routing excess water for other beneficial purposes) aiming for the environmental sustainability. Nevertheless, the future prediction of hydropower production is very complex due to the nonlinear nature of the input functions along with spatial and temporal variations of the meteorological datasets such as rainfall, temperature, and evaporation [8]. The output from prediction models may have high economic value in regulating sustainable energy development projects such as hydropower [9].

Many researchers have studied the impact of climatic variation on hydropower generation mostly using Global/ Regional Climate Models (GCMs/RCMs), trend analysis, and statistical downscaling methods (e.g., [10-12]). Few studies have focused on the economic impact of climate change on hydropower (e.g., [13]), while some researchers have used an assessment and comparison approach to quantify the effects of climate change on hydropower generation [14]. For example, [15] interestingly used a distributed hydrological model together with an optimal operational reservoir model to predict future hydropower generation of large-scale reservoir groups in the upper Yangtze River basin, China.

Currently, intelligent machine learning techniques such as Artificial Neural Network (ANN), Genetic Algorithms, fuzzy logic, Multilayer Perceptron (MLP), Support Vector Regression (SVR), and Random Forest (RF) approaches are dominantly being used in hydrological prediction to understand the role of climate change on water-energy nexus [16] including the hydropower generation. To the present date, the majority of past research in the hydropower engineering sector is focused on the study of overall risk management of the hydropower industry (almost 35\%), while only $16 \%$ of research is focused on studying the impact of climate change on hydropower generation [17]. The authors reckon a substantial number of studies are needed to monitor the impact of climate change on the hydropower industry, especially in countries, which are heavily dependent on hydropower for stabilizing power requirements. ANNs showcase a potential solution paradigm for these issues.

ANNs are "data-driven" models having mathematical computation capability analogous to the human nervous system and brain functions utilizing statistical techniques to recognize patterns between input variables and output variables [18]. ANNs have been efficiently used to predict and classify future operations of hydropower plants through past data observations. The study in [19] concluded that ANN is a versatile tool to predict storage of water in hydropower reservoirs while conducting a case study in Nigeria at Jebba and Kainji reservoirs using independent input parameters such as reservoir inflow, reservoir storage, reservoir elevation, plant use coefficient, tail race level, release from a turbine, and evaporation losses. A similar study was conducted by [20], where the authors discovered an upward trend in hydropower generation at Jebba, Kainji, and Shiroro hydropower reservoirs. The study in [21] used ANN to predict future hydroelectric generation using the artificial bee colony algorithm in Turkey using input variables such as electricity demand, energy use, population, and temperature and found that electricity generation in Turkey is not in line with the country's vision to produce $30 \%$ of its electricity from renewable resources by 2023. In addition, the study in [22] analyzed future streamflow up to 2040 for the Ranganadi river in India to project hydropower generation using 3 GCM models along with ANN. Patil has shown the catchment area would face flooding issues; however, there would also be an increase in hydroelectricity production due to abundant water.

The study in [8] suggested that characteristics of input parameters play a dominant role in predicting future power generation when using feed-forward backpropagation algorithms in the ANN platform. They used the conclusions from their work on predicting the future performance of the Himreen Lake Hydropower Plant located in Iraq. The power production, flow rate of water, and turbine head were the input parameters for their study. In addition, [23] recommended ANN-ARIMA hybrid model instead of ANN for predicting future data of renewable energy resources (e.g., hydroelectricity, solar, and wind) while forecasting electricity generation from various energy resources in the USA. The study in [24] has further supported this argument to couple ANN with supervised or unsupervised learning algorithm to enhance reservoir outflow prediction after reviewing 66 papers, which employed ANN for optimizing reservoir operations. Furthermore, the study in [17] has suggested conducting future research, which is related to risk management on hydropower, using a fuzzy model combined with ANN and genetic algorithm.

Several researchers have highlighted the benefit of ANNs in hydropower prediction. The study in [25] revealed hidden neurons have a greater impact on the performance of the ANN model while predicting water discharge at a hydropower reservoir located in Malaysia. In addition, [26] revealed that ANN models are the most accurate in predicting short-term and long-term hydropower generation after conducting case studies in run-of-the-river (ROR) type of hydropower located in France, Portugal, and Spain using historical meteorological data such as precipitation, snowfall, and temperature.

However, to the authors' knowledge, there was only one study in Sri Lanka to forecast the power generation using ANN. The study in [27] has forecasted solar power using ANN. In addition, the study in [28] has forecasted the daily electricity demand; however, forecasting power generation was not carried out. Nevertheless, as it was stated earlier, there are not any studies conducted in Sri Lankan watersheds linked with hydropower plants to forecast the future power generation using ANNs. Therefore, for the first time in the context of Sri Lanka, a hydropower forecasting model is presented herein using the ANN. In this paper, we 
examine the capability of ANNs to forecast the future hydropower generation by using historical rainfall data for training as well as validating the forecasting model and future rainfall data extracted from the regional climate model (Coordinated Regional Downscaling ExperimentCORDEX) for forecasting the future power generation through a feed-forward with backpropagation algorithm.

The main objective of this study is to check the performance of the Samanalawela hydropower plant, which is a reservoir type of plant in the perspective of climate variability. Due to the lack of other meteorological variables such as air temperature, humidity, which could be used as input variables to the model, we only used rainfall data for training and validating the ANN model. The authors reckon this research would be beneficial in optimizing the usage of water collected in the reservoir for various uses such as hydropower production and irrigation. This research may be important to water resource planners and government authorities to manage water resource projects by monitoring the trend in hydropower production.

\section{Sri Lanka and Its Hydropower Generation}

Sri Lanka has an installed capacity of 1,719 Megawatts (MW) of hydroelectric power and current commitments on hydropower development would add around $247 \mathrm{MW}$ to the national grid in the coming years [2]. Most of the hydropower stations in Sri Lanka are aged over 25 years of their total lifespan [29]. Though hydropower plants have a long life of around 50 years, if any of the older hydropower plants stops functioning, either due to consequences of climate change or mechanical failure, then Sri Lanka would have to face power shortage issues as it would be difficult for the country to substitute the botched hydropower plants in a short period. Hence, the assessment of the power generation capacity of hydropower plants is essential in the Sri Lankan context. This is to manage the power needs for a growing economy and then to regulate water resource development projects in the context of climate variability. However, there are limited studies conducted in Sri Lanka to analyze future power generation from running or planned hydropower plants. The study in [30] studied ways to increase power generation in hydropower plants by controlling soil erosion, reservoir siltation in Uma Oya basin, which is regarded to be one of the most important catchments in Sri Lanka. The study in [31] studied inflows in the Kotmale reservoir using El Nino Southern Oscillation (ENSO) phase index for the period of 1960 to 2005 and found that the inflows to the reservoir have decreased, altering hydropower production and irrigation plan. The study in [32] using GCMs based studies (mainly rainfall) projected that the future production capacity of the hydropower plants in the Mahaweli basin would increase as a result of an increase in consecutive wet days, decrease in consecutive dry days, and increase in annual total precipitation. In addition, [11] used a multiyear rainfall trend analysis where they found climate change would not influence the power generation of Denawaka Ganga minihydropower located in the Rathnapura district. The study in [33] has also put efforts to study the impact of climate change on the Erathna minihydropower plant located in the Rathnapura district. They have concluded that there would be a decrease in power generation in future years. The study in [34] further performed a similar study considering the newly functioned Uma Oya basin, where the authors clarified there would be no major threats to hydropower production in the coming years due to scarcity of water in the basin area. However, as it was stated in the introduction section, there is no comprehensive study on forecasting hydropower in Sri Lanka for future years. Therefore, this research work has a greater potential in attracting the authorities' attention for better planning and control processes in hydropower stations in Sri Lanka.

\section{Future Climate Data Extraction}

Global climatic models (GCMs) provide climatic information on large scales covering vastly differing landscapes, whereas regional climatic models (RCMs) are applied over much smaller scales (typical horizontal resolution $10-50 \mathrm{~km}$ ), which may provide much detailed information for adaptation assessment and planning [35]. GCMs forecast the climate variation of the Earth in the future as a forecasted tool. However, they should be studied under regional or even national scales to reveal effective adaptation strategies.

The four RCMs used in this research for extracting future climatic data are ACCESS_CCAM, MPI_ESM_CCAM, CNRM_CCAM, and REMO2009. These RCMs were developed by the Commonwealth Scientific and Industrial Research Organization (CSIRO) from CORDEX. The corresponding GCMs of the RCMs used are ACCESS 1.0, MPI_ESM_LR, CNRM_CM5, and ECHAM-4 GCM [36-40].

The future climate data can be extracted for different scenarios. Representative Concentration Pathways (RCP) are such scenarios from which the climate data can be extracted. RCPs are trajectories, which are based upon greenhouse gas concentrations adopted by the Intergovernmental Panel on Climate Change [41]. Four RCPs are widely used in the literature and they are RCP2.6, RCP4.5, RCP6.0, and RCP8.5 [41]). RCP4.5 can be described as the intermediate emission scenario, where the emissions will start declining by approximately 2045 , whereas RCP 8.5 is defined as the higher emission scenario, where emissions continue to increase throughout the $21^{\text {st }}$ century. For further details on RCP, states can be found in $[42,43]$.

It is a well-known fact that RCMs suffer from varying levels of systematic biases $[44,45]$. The reasons for such biases may be due to systematic model errors caused by imperfect conceptualization, discretization, and spatial averaging within grid cells. To deal with these biases, several bias correction methods such as linear scaling, local intensity scaling, power transformation, variance scaling, distribution transfer, and delta change approach are used in the literature [46].

Due to the simplicity and fast application, Linear Scaling (LS) method [47] has been widely used in many studies. LS is capable of adjusting all climatic factors to an acceptable level, where errors in precipitation are adjusted with the use of a 
multiplier [48-51]. Linear scaling bias correction method can be applied using the two equations given below (equations (1) \& (2)) where cor, his, obs, sim, $P$ and $d$ stand for bias-corrected data, raw RCM data, observed data, raw RCM corrected data, precipitation and daily, respectively, and $\mu_{m}$ stands for a long-term monthly mean of precipitation data:

$$
\begin{gathered}
P_{\mathrm{his}, d}^{\mathrm{cor}}=P_{\mathrm{his}, d} * \frac{\mu_{m}\left(P_{\mathrm{obs}, d}\right)}{\mu_{m}\left(P_{\mathrm{his}, d}\right)}, \\
P_{\mathrm{sim}, d}^{\mathrm{cor}}=P_{\mathrm{sim}, d} * \frac{\mu_{m}\left(P_{\mathrm{obs}, d}\right)}{\mu_{m}\left(P_{\mathrm{his}, d}\right)} .
\end{gathered}
$$

\section{Study Area}

The Samanalawewa Hydropower Project area is in the Belihul Oya area, Rathnapura district, Sabaragamuwa province, in the central region of Sri Lanka. The project was completed in 1992, just downstream of the convergence point of the Walawe River and Belihul Oya. The catchment area $\left(359 \mathrm{~km}^{2}\right)$ can be physiographically categorized as midland, consisting of marbles, quartz with an average altitude of about $530 \mathrm{~m}$ [52]. The area lies in the wet zone of the country, which receives an average annual rainfall of around $2500 \mathrm{~mm}$ [53]. The project area receives most of the rainfall from the southwest monsoon, while small influences are experienced from northeast monsoon and intermonsoon cyclones. Samanalawewa Hydropower Project consists of a $u$-shaped reservoir (as it is shown in Figure 1), a waterway system, a small irrigation canal, a minihydropower plant, and a $120\left(2^{*} 60\right)$ Megawatts (MW) power plant for hydroelectricity generation. A detailed catchment map is shown in Figure 1.

The study area has many agricultural lands with significant forest cover. The irrigated water from the dam is essential to downstream villages like Kaltota, Madabadda (left \& right), Welipotayaya, and Koongahamankada for agricultural purposes. Paddy yield reduction by $11.5 \%$ has been reported in the regions located downstream of the study area because of the scarcity of water in the reservoir [54].

Samanalawewa hydropower is one of the largest and the oldest reservoir-type power plants in Sri Lanka, and over the years, it has been playing a dominant role in stabilizing power supply at peak hours. It contributes to $8.69 \%$ out of all large hydropower systems in generating power to meet electricity demand in Sri Lanka. This project, starting from its construction, has gained significant attraction due to the water leakage problem encountered from the right bank of the dam because of the poor geologic condition [55]. In addition, there were several environmental concerns during the project planning phase; however, no greater attention was given as there were no strict environmental regulation obligatory in major development works [56]. Though the provision for Environmental Impact Assessment (EIA) was established in Sri Lanka in 1988, EIA during the planning of
Samanalawewa was conducted partially focused on vegetation replantation and ecosystem preservation.

Due to the leakage, phase II construction of hydropower plant (120 MW capacity) was suspended; instead, a minihydropower plant was built, which operates using the leaked water. Even after a tremendous effort from Ceylon Electricity Board (CEB) to stop the leakage, impounded water is leaking approximately at the rate of $2.1-2.8 \mathrm{~m}^{3} / \mathrm{s}$ [57]. Analysis of future water availability in the Samanalawewa reservoir in terms of power generation is essential as a portion of seized water is directly supplied to irrigation without passing the power station and another portion (leaked portion) goes to minihydropower plants producing comparatively lesser energy. Additionally, with the increasing requirement of water from downstream areas for irrigation, water management at the Samanalawewa reservoir needs to be more engineered. Moreover, climate variability might influence negatively or positively on water resource management objectives led out by CEB at Samanalawewa hydropower plant. Hence, the presented research herein would be interested in the many stakeholders of the Samanalawewa Hydropower Project.

\section{ANN Model Development}

To identify the impact of climatic variation (in terms of precipitation) on hydropower generation at Samanalawewa hydropower station, monthly rainfall data of four gauging stations at Alupola (annual mean rainfall-4272 $\mathrm{mm}$ ), Detangalla (annual mean rainfall-2843 mm), Balangoda (annual mean rainfall-2170 mm), and Belihul Oya (annual mean rainfall-2704 $\mathrm{mm}$ ) were used. The catchment is one of the data scarcity catchments in the country and only some of the rainfall data are available even at the gauging stations. Therefore, the model development has to rely on the available data. The annual rainfall distributions over the 30 years are given in Figure 2 for more information.

The numerical computing software MATLAB (version 9.4.0.813654-R2018a) was used to develop the ANN model. The ANN model is composed of an input layer, an output layer, and a hidden layer with neurons linking each layer to the other by interconnecting weights. In a feed-forward neural network, the hidden layer performs all the computations and the output layer does the prediction. Training the neural network generally refers to discovering the weights for links between neurons. In this study, the monthly rainfall data of the four stations from 1996 to 2016 was used as the input parameter and the power generation at Samanalawewa power station was used as the target parameter while training the ANN model. The historical rainfall data was collected from the Department of Meteorology, Sri Lanka, while power generation data were collected from the Ceylon Electricity Board, Sri Lanka. The nonlinear relationship between rainfall and power generation can be expressed as in the following equation:

$$
\text { power generation }=\phi\left(\text { rainfall }_{i}\right) \text {, }
$$

where $\phi$ represents the nonlinear function between the power generation and the rainfall, while $i$ represents the rain 


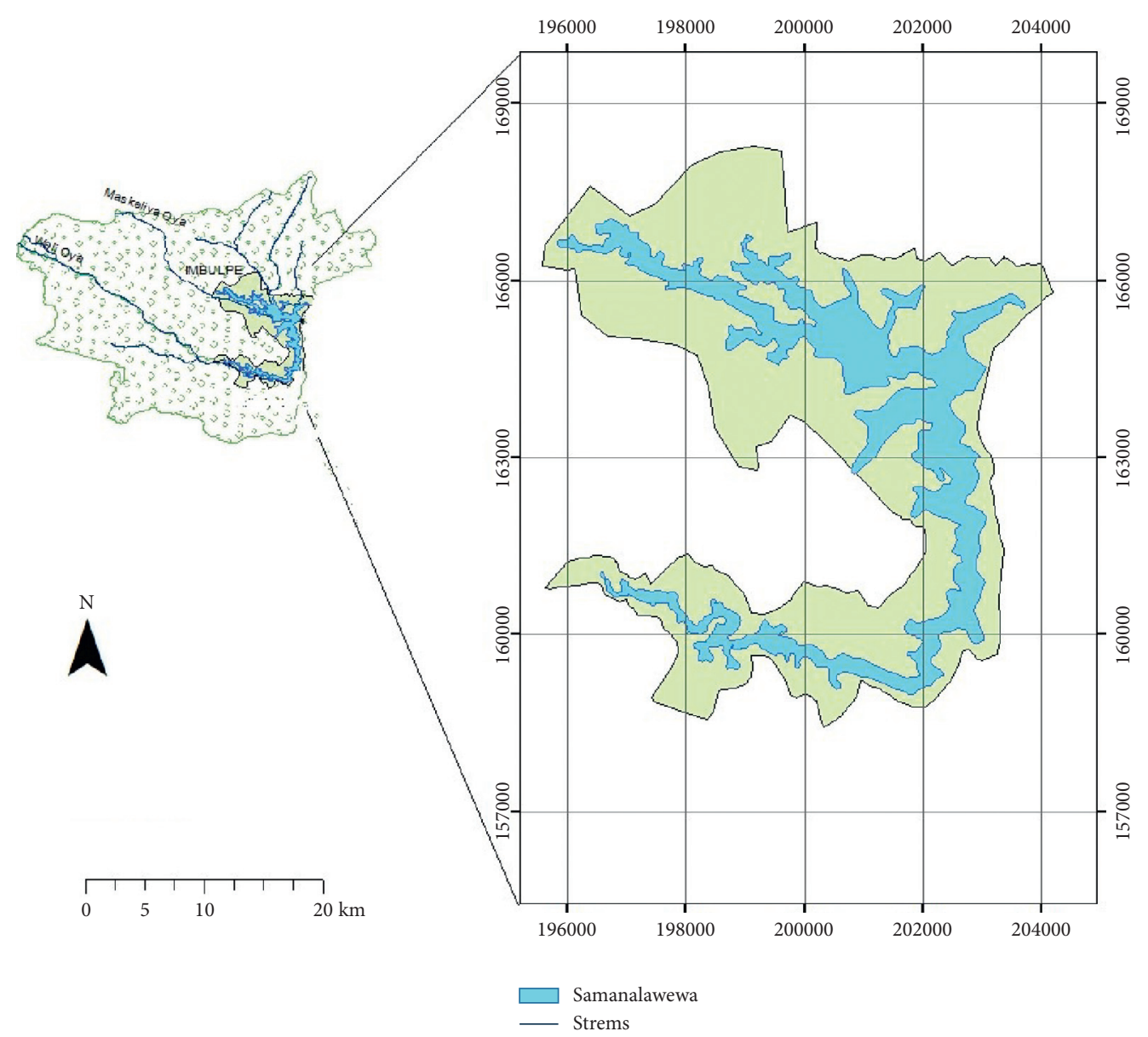

Figure 1: Samanalawewa catchment.

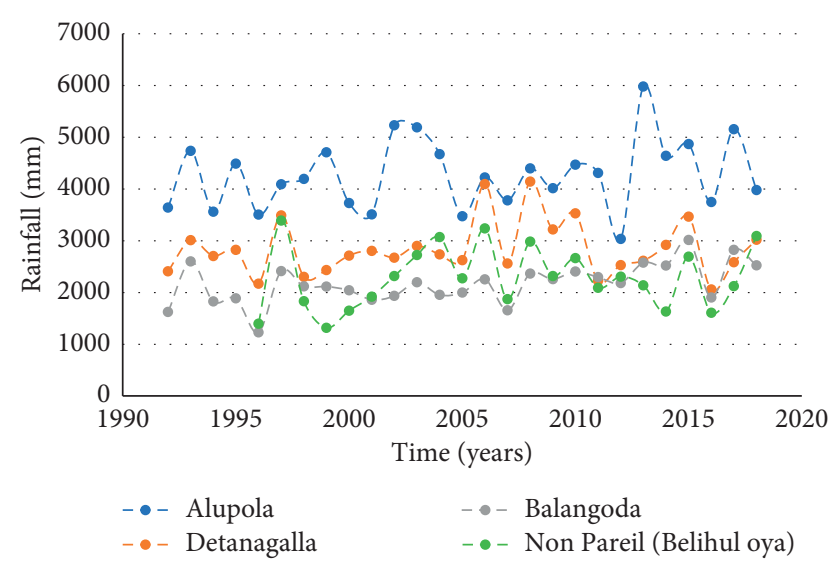

FIgURE 2: Annual rainfall distribution in Samanalawewa catchment.

gauges. Out of the overall input data, $70 \%$ of data were used to train the neural network, whereas $15 \%$ of data were used for validation and the other $15 \%$ were used to test the network.

Though most of the past literature supports ANN models to be one of the powerful soft computing tools in predicting future hydropower generation either from minihydropower type or reservoir type hydropower plant, still deep understanding is required on the selection of independent input parameters and the type of algorithm to be used in ANN model, which would best resemble real-time climate change scenarios to give best estimates for future hydropower generation. However, there are not any specific rules to organize ANN configuration [58]. The range of hyperparameters was determined based on the authors knowledge and experience and the availability of the data. Two hidden layers were used with 10 hidden neurons and LEARNGDM was used as the adaptation learning function. Optimum neuron number in the hidden layer was determined using a trial and error procedure by varying the hidden neuron number from 5 to 30 , with increments of five. The linear transfer function (purelin) and hyperbolic tangent sigmoid transfer function (tansig) were applied to the hidden and output layers of the network as the simulation function. The number of iterations varied between 5 and 10 . The conceptual diagram of the developed ANN model is shown in Figure 3.

The developed ANN model was trained using seven training algorithms, namely, BFGS, Quasi Newton (BFG), Polak-Ribiére conjugate gradient (CGP), Conjugate gradient with Powell/Beale Restarts (CGB), Fletcher-Reeves conjugate gradient algorithm (CGF), Levenberg-Marquadt (LM), 


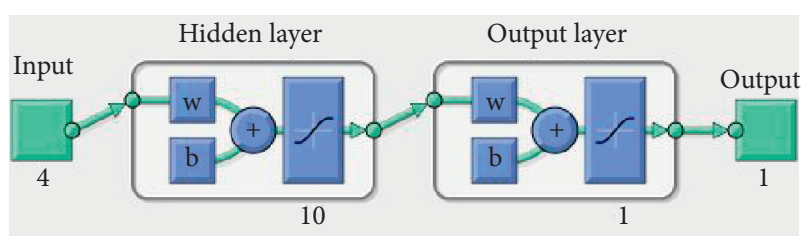

Figure 3: Conceptual diagram of the ANN model.

Resilient Backpropagation (RP), and scaled conjugate gradient (SCG) algorithms. These algorithms have outperformed many other algorithms and are widely used in engineering applications [59-63].

The best performing network was chosen based upon the coefficient of correlation $(R)$, mean squared error (MSE), and the computational efficiency in terms of the number of epochs. Many researchers used either $R$ and MSE [64-66] or the coefficient of determination $\left(R^{2}\right)$ and root mean square error (RMSE) [67-70] to check the performance of the ANN models. It was found that the BFGS Quasi Newton (BFG) vanquished all other algorithms. Therefore, the ANN trained with the BFG algorithm was selected to be used for the future projection process. The saved ANN model was validated by using monthly rainfall data of the years 2017-2018. The use of independent validation sets is very vital in ANN development to avoid overfitting of the training data as well as to verify the quality of the trained model [71].

The future climate data were extracted from RCMs using CORDEX for the period between the years 2021-2050. However, out of the four RCPs, only RCP 4.5 and RCP 8.5 were used for the forecasting stage. The linear scaling technique was then used to correct the bias on the rainfall data. The forecasted but bias-corrected rainfall data were used as the input of the developed ANN model to project the power generation of the Samanalawewa Hydropower plant.

\section{Results}

Table 1 depicts the correlation coefficients ( $R$ value) and performances for different algorithms for different cases. With $R$ value greater than $0.6, \mathrm{BFG}$ and CGB algorithms have produced proficient training results. Though $R$ values of 0.5-0.6 obtained during training cannot be considered promising for prediction purposes in the normal condition, they are acceptable especially based on input characteristics used in training. The spatial variation of rain gauges along with the spatiotemporal variation of precipitation, which is the chief input in this ANN model, could have negatively impacted on $R$ values. On the other hand, $R$ values might have got lowered due to a nonlinear relationship between input and output variables along with a scattering of data in a broad scale. However, the values obtained are adequate for forecast future hydropower generation. Based on the lower MSE value out of 2 algorithms, the BFG algorithm was selected for validation and prediction purposes.

Figure 4 presents the results from the ANN model under the BFG training algorithm for different stages, including training, validation, test, and everything together. Even though the model was developed for a significant number of data set, the overall acceptability is not the highest $(R>0.9)$. This can be understood from the coefficient of correlation between the observed and predicted power generations. Nevertheless, the validation process has a good correlation $(R>0.8)$; therefore, the selection of using the BFG training algorithm can be justified.

Figure 5 presents the validation results conducted after the culminating training ANN model. The developed projected model was validated to the years 2017 and 2018 . Therefore, Figure 5 shows the relationship between the forecasted power generation from the ANN model to the observed power generation in the Samanalawewa reservoir. The determination coefficient $\left(R^{2}=0.83\right)$ is high and therefore, the validation process for forecasting can be accepted.

Figure 6 illustrates the forecast of hydropower generation from 2020 to 2050 for two different emission scenarios, RCP4.5 and RCP8.5. The comparison of power generation for two scenarios is given in Figure 6. Until 2039, power generation under the RCP4.5 scenario is higher than for RCP8.5. However, from 2040 the power generation trend follows reverse order, where lesser power is generated under RCP8.5. Under the RCP4.5 condition, a decreasing trend of power production is discovered in future years, which would get lowered to as much as $173 \mathrm{GWH}$ in 2036, while peak production is observed in 2031, generating $446 \mathrm{GWh}$ energy. On the other hand, slightly increasing drift on power generation is observed under the RCP8.5 scenario, where peak production is in 2045 engineering $406 \mathrm{GWh}$, while the lowest production is in 2037 generating $211 \mathrm{GWh}$ energy.

Figure 7 shows the historical power generation at the Samanalawewa hydropower plant. The historical plot of power generation shows an increasing trend of power production (visible trend from the trend-line drawn) from hydropower plants starting from 1992 to 2019 with maximum power generated in 2015 producing $425 \mathrm{GWh}$ of energy. Comparing historical power generation and projected future power generation, it is certain Samanalawewa hydropower plant would continue to produce energy equivalent or slightly higher than the amount it has been generating in the past years. However, the generation has to be limited to the capacity of the power turbines. Moreover, close monitoring of historical and future power generation to illuminate RCP8.5 scenario is much favorable rather than RCP4.5 in terms of power generation at Samanalawewa hydropower plant.

\section{Discussion}

Samanalawewa reservoir is currently functioning as a multipurpose reservoir, which sustains various objectives, though it was initially designed as a single-purpose project. The main target of this study was to project the future power generation at Samanalawewa hydropower in the perspective of climate variability. The annual power generation after partially resolving the leakage problem was premeditated at $403 \mathrm{GWh}$ /year. However, the actual average annual power generation during the period of 1993-2005 was $274 \mathrm{GWh} /$ year. A considerable difference of $129 \mathrm{GWh}$ has been 
TABLE 1: Correlation coefficients for ANN results.

\begin{tabular}{|c|c|c|c|c|c|}
\hline \multirow[b]{2}{*}{ Algorithm } & \multicolumn{3}{|c|}{ Correlation coefficients } & \multirow{2}{*}{\multicolumn{2}{|c|}{$\begin{array}{c}\text { Performance } \\
\text { MSE }\end{array}$}} \\
\hline & Training & Validation & Test & & \\
\hline BFG & 0.62 & 0.82 & 0.64 & 0.67 & 86 \\
\hline CGB & 0.59 & 0.67 & 0.60 & 0.61 & 90 \\
\hline $\mathrm{RP}$ & 0.53 & 0.58 & 0.70 & 0.56 & 84 \\
\hline LM & 0.55 & 0.55 & 0.57 & 0.55 & 86 \\
\hline SCG & 0.57 & 0.65 & 0.17 & 0.52 & 114 \\
\hline CGF & 0.42 & 0.74 & 0.53 & 0.49 & 99 \\
\hline CGP & 0.52 & 0.41 & 0.35 & 0.49 & 102 \\
\hline
\end{tabular}

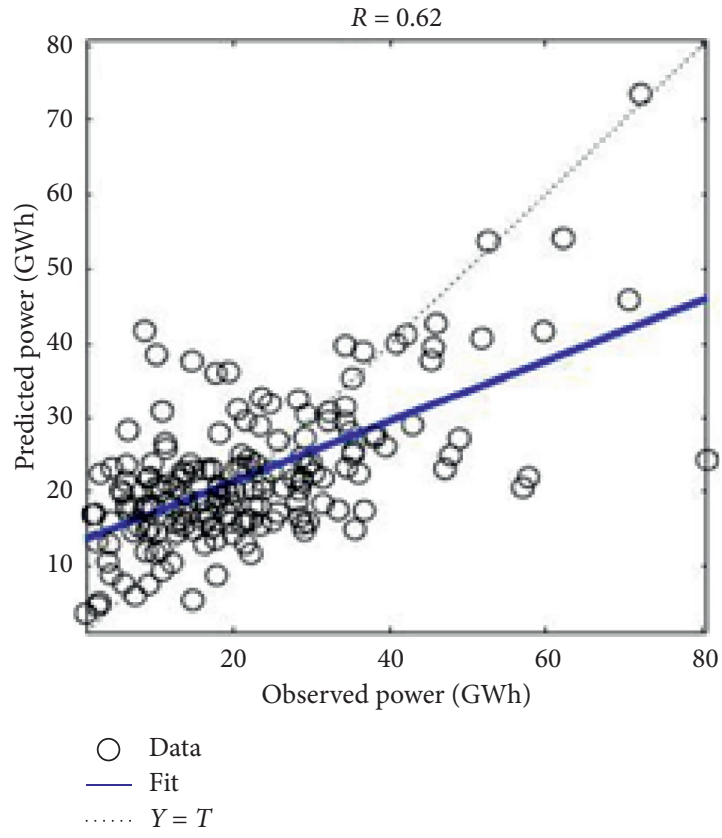

(a)

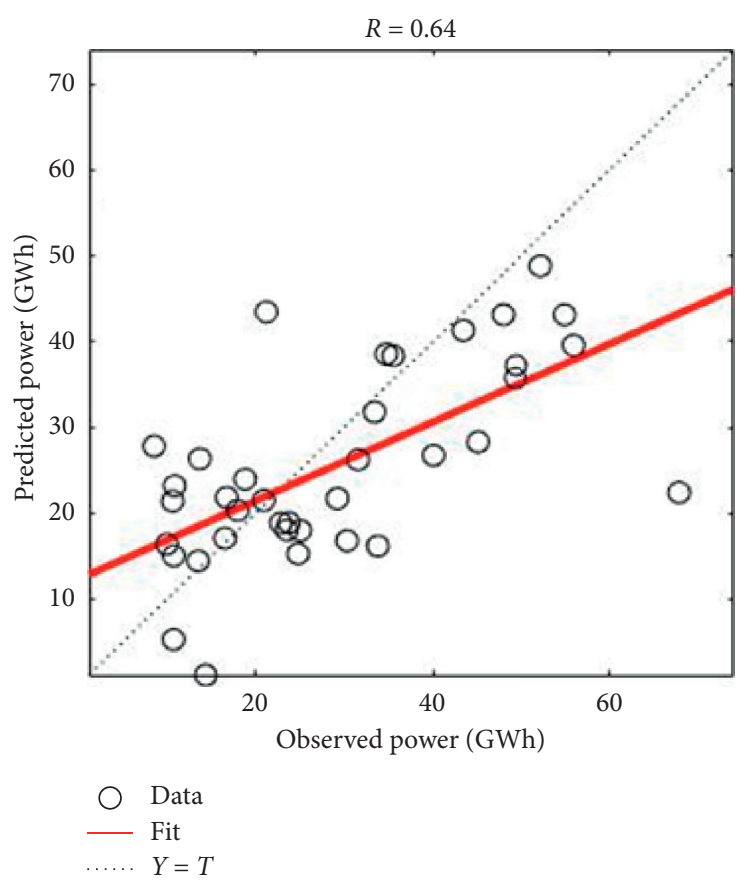

(c)

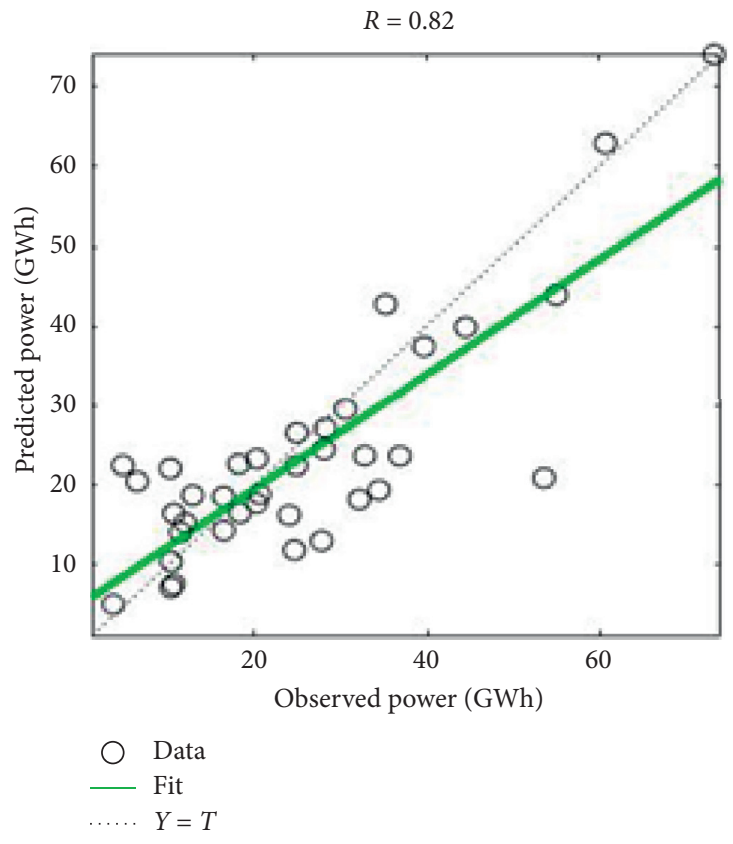

(b)

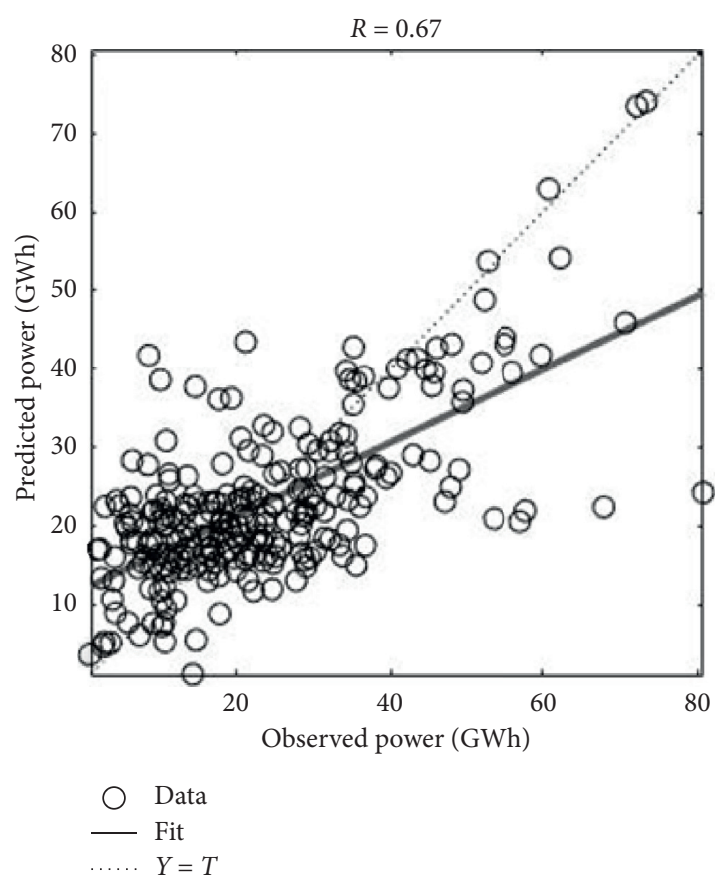

(d)

FIGURE 4: ANN results under the BFG training algorithm. (a) For training, (b) for validation, (c) for test, and (d) for all. 


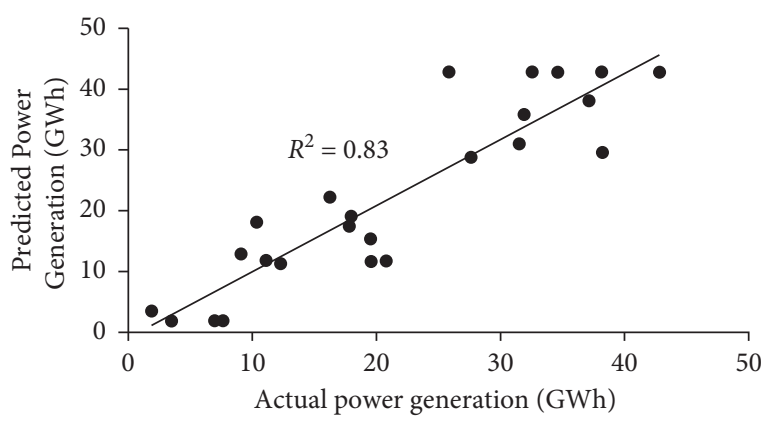

Figure 5: Validation results of the developed ANN model.

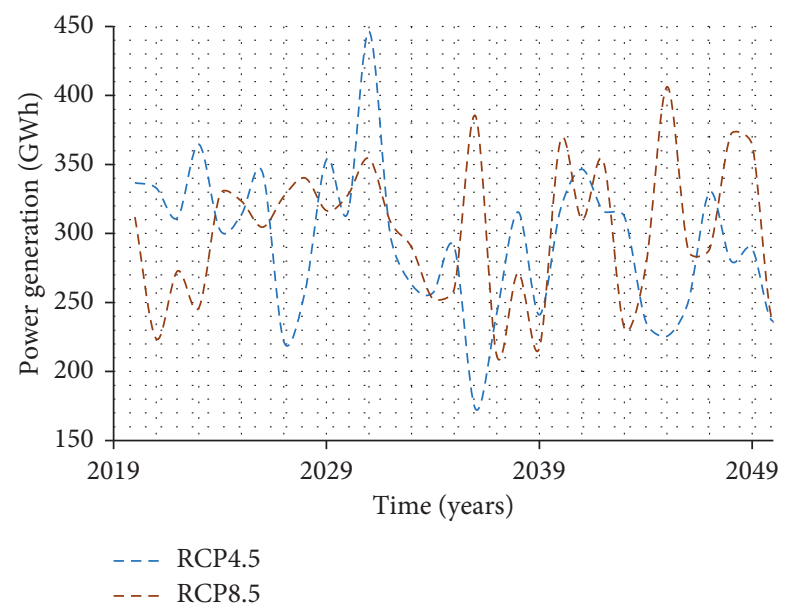

Figure 6: Power generation forecast for RCP4.5 \& RCP8.5 scenarios.

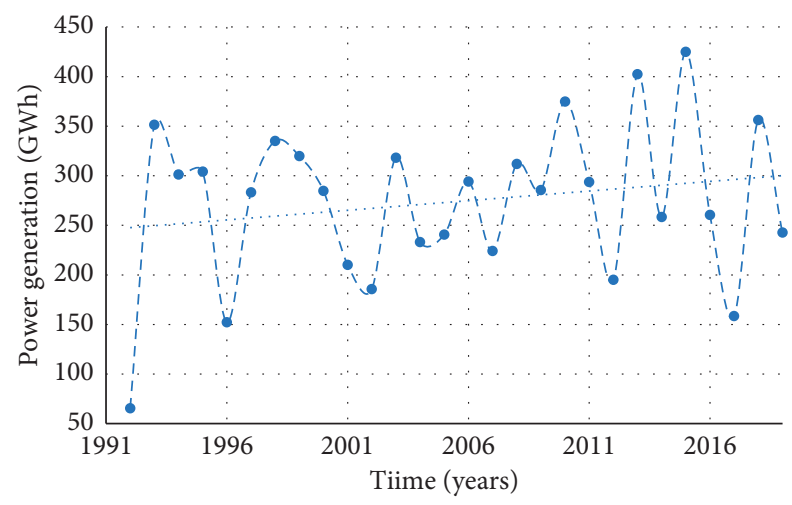

Figure 7: Historic power generation with time.

observed between planned and actual power production in past years. Therefore, other than the reduction of runoff received to the reservoir, increasing demand for agricultural purposes can be a reason for the power generation reduction.

Initially, it was decided to release 50 million $\cdot \mathrm{m}^{3}$ for the year for agricultural purposes from the Samanalawewa reservoir; however, due to the various pressures and stresses from the local people and authorities, the agricultural release was increased to 80 million $\cdot \mathrm{m}^{3}$ per year. Therefore, a reduction of $35 \mathrm{GWh}$ of power can be expected from the hydropower plant [72].

However, it was found out that Samanalawewa hydropower generation may not be wedged by climate variability until 2050. Hydropower generation was found to increase in future years until 2050 because of the abundant water in the reservoir under both tested RCP scenarios. The annual average forecasted power generations undertested RCP scenarios (RCP4.5 and RCP8.5) for years 2020 to 2050 are $294 \mathrm{GWh} /$ year and $302 \mathrm{GWh} /$ year, respectively. Therefore, the forecasted increases in power production under RCP4.5 and RCP 8.5 scenarios are $7.29 \%$ and $10.22 \%$, respectively. If water release from Samanalawewa is controlled to a limit, where it harvests electricity as it used to generate in the past, there will be some excess water in the reservoir, which can perhaps be diverted to other demanding sectors such as agriculture.

However, the forecasted increase in power generation is not uniform (refer to Figure 6). Nonuniformity is also a likely effect of climate variation, where the wet season would continue to get more rainfall, whereas the dry season would get drier due to less precipitation. This adds major challenges in developing a concrete strategy for the overall management of reservoir operations. Low power generation in a particular year specifies Samanalawewa catchment receiving less rainfall in that particular year and vice versa. This indicates the management of water can get complicated in certain years due to prolonged drought or excessive rainfall, resulting in natural disasters.

Hence, this study is of paramount importance to the representatives from various agencies to plan resources based on the forecasts. Water release from hydropower plants for electricity generation and irrigation at Samanalawewa is controlled by representatives from the Ceylon Electricity Board, Water Management Secretariat, Mahaweli Authority, and National Water Supply and Drainage Board. Therefore, the meetings which are held weekly [73] would be much fruitful from the results presented herein.

Nevertheless, the accurate projection of power generation from any hydropower plant is challenging as well as uncertain due to its dynamics. In addition, forecasts from ANN models are reliant on the quality and availability of the input and output parameters. In this study, rainfall and power generation data of the past 21 years were used with only 1 type of input climatic variable. This could be the probable reason to have obtained high MSE values during the training of the ANN model. The authors, therefore, reckon more accurate projections can be made by incorporating comprehensive input parameters, which play an influencing role in hydropower generation provided that relevant data are available. Furthermore, the authors suggest performing seasonal and monthly projections to visualize the supply of water in deeper scales.

\section{Conclusions}

An ANN model was efficaciously implemented to forecast the future power generation at the Samanalawewa hydropower plant. As it was already stated, this is novel research 
work in the Sri Lankan context, which also can be used in forecasting the hydropower generation. BFG algorithm was found to be the best training algorithm among the tested other training algorithms for the developed ANN model to predict the hydropower generation. Results revealed that the power generation would increase by $7.29 \%$ and $10.22 \%$ under RCP4.5 and RCP8.5 scenarios, respectively, until 2050. This is a significant contribution to the energy demand in Sri Lanka, and more importantly, the forecasted increase is from renewable energy. This highlights that there are not any significant intimidations of climate variability in the Samanalawewa catchment area. This is an advantageous finding for the energy authorities in Sri Lanka due to the scarcities of power generations. However, the authors realize that representatives from various agencies have a vital role to play, as the forecasted increase in hydropower generation is not uniform. Hence, this study provides some clues to stakeholders to preplan natural disasters such as drought and flooding to minimize associated risks.

However, the developed forecasting model is only formulated using the rainfall to the catchment. The other climate variables, such as temperature, evapotranspiration, wind speed and direction, relative humidity, and soil infiltration, would be useful in a comprehensive forecasting model development. Nevertheless, the developed forecasting model can be effectively used in a climatic data scarcity environment. Most of the developed countries do not have an improved network of meteorological stations; even the available stations only record the rainfall. Therefore, the developed model is extremely important, at least to have some clues for the future.

In addition, the presented ANN model can be used to forecast the future power generation from hydropower plants located elsewhere. Therefore, the authors suggest carrying out similar projection studies using ANN for all the major hydropower plants located in Sri Lanka and to have a common management plan of water resources to generate hydropower for the future. However, it is always important to plan for the uncertainty in the neural network models due to the forecasted future climates rather than the observed climatic parameters.

\section{Data Availability}

The climatic data and the analysis data are available from the corresponding author upon request.

\section{Disclosure}

The research was carried out in the Sri Lanka Institute of Information Technology Environment.

\section{Conflicts of Interest}

The authors declare that there are no conflicts of interest.

\section{Acknowledgments}

The authors would like to appreciate Dr. Kamal Laksiri, Project Director, Broadlands Hydropower Project, Ceylon
Electricity Board, Sri Lanka, for support which is given in obtaining hydropower generation data from Samanalawewa Hydropower Project.

\section{References}

[1] WEC (World Energy Council), Energy Resources: Hydropower, WEC (World Energy Council), London, UK, 2019.

[2] Asian Development Bank (ADB), Sri Lanka Energy Sector Assessment, Strategy, and Road Map, Asian Development Bank (ADB), Mandaluyong, Philippines, 2019.

[3] The World Bank, "Directions in hydropower: scaling up for development," in Water Working NotesThe World Bank, Washington, DC, USA, 2009.

[4] International Hydropower Association (IHA), Hydropower Status Report, IHA Central Office, London, UK, 2019.

[5] G. Chen and G. D. Costa, "Climate change impacts on water resources case of Sri Lanka," Environment and Ecology Research, vol. 5, no. 5, pp. 347-356, 2017.

[6] G. Naveendrakumar, M. Vithanage, H.-H. Kwon, M. C. M. Iqbal, S. Pathmarajah, and J. Obeysekera, "Five decadal trends in averages and extremes of rainfall and temperature in Sri Lanka," Advances in Meteorology, vol. 2018, Article ID 4217917, 13 pages, 2018.

[7] X. Zhang, H.-Y. Li, Z. D. Deng et al., "Impacts of climate change, policy and water-energy-food nexus on hydropower development," Renewable Energy, vol. 116, pp. 827-834, 2018.

[8] A. Hammid, M. Sulaiman, and A. Abdalla, "Prediction of small hydropower plant power production in Himreen Lake dam (HLD) using artificial neural network," Alexandria Engineering Journal, vol. 57, no. 1, pp. 211-221, 2017.

[9] D. Yadav and N. Veena Sharma, "Artificial neural network based hydro electric generation modelling," International Journal of Applied Engineering Research, vol. 2, no. 1, pp. 56-72, 2010.

[10] M. S. Khan, P. Coulibaly, and Y. Dibike, "Uncertainty analysis of statistical downscaling methods," Journal of Hydrology, vol. 319 , no. $1-4$, pp. 357-382, 2006.

[11] B. Khaniya, H. Priyantha, N. Baduge, H. Azamathulla, and U. Rathnayake, "Impact of climate variability on hydropower generation: a case study from Sri Lanka," ISH Journal of Hydraulic Engineering, pp. 1-9, 2018.

[12] P. Qin, H. Xu, M. Liu et al., "Climate change impacts on three Gorges reservoir impoundment and hydropower generation," Journal of Hydrology, vol. 580, Article ID 123922, 2020.

[13] S. Mishra, T. Veselka, A. Prusevich et al., "Differential impact of climate change on the hydropower economics of two river basins in high mountain Asia," Frontiers in Environmental Science, vol. 8, no. 26, 2020.

[14] S. K. Mishra, J. Hayse, T. Veselka et al., "An integrated assessment approach for estimating the economic impacts of climate change on river systems: an application to hydropower and fisheries in a Himalayan river, Trishuli," Environmental Science \& Policy, vol. 87, pp. 102-111, 2018.

[15] W. Zhong, J. Guo, L. Chen, J. Zhou, J. Zhang, and D. Wang, "Future hydropower generation prediction of large-scale reservoirs in the upper Yangtze river basin under climate change," Journal of Hydrology, vol. 588, Article ID 125013, 2020.

[16] S. Zaidi, V. Chandola, M. Allen et al., "Machine learning for energy-water nexus: challenges and opportunities," Big Earth Data, vol. 2, no. 3, pp. 228-267, 2018. 
[17] A. Shaktawat and S. Vadhera, "Risk management of hydropower projects for sustainable development: a review," Environment, Development and Sustainability, 2020.

[18] H. I. Mohamed, "Design of alluvial Egyptian irrigation canals using artificial neural networks method," Ain Shams Engineering Journal, vol. 4, no. 2, pp. 163-171, 2013.

[19] T. S. Abdulkadir, A. W. Salami, A. R. Anwar, and A. G. Kareem, "Modelling of hydropower reservoir variables for energy generation: neural network approach," Ethiopian Journal of Environmental Studies and Management, vol. 6, no. 3, pp. 310-316, 2013.

[20] A. Salami, A. Mohammed, J. Adeyemo, and O. Olanlokun, "Modeling of reservoir inflow for hydropower dams using artificial neural network," Nigerian journal of Technology, vol. 34, no. 1, pp. 28-36, 2015.

[21] E. Uzlu, A. Akpınar, H. T. Özturk, S. Nacar, and M. Kankal, "Estimates of hydroelectric generation using neural networks with the artificial bee colony algorithm for Turkey," Energy, vol. 69, pp. 638-647, 2014.

[22] M. Patil, "Stream flow modeling for Ranganadi hydropower project in India considering climate change," Current World Environment, vol. 11, no. 3, pp. 834-845, 2016.

[23] M. Khodaverdi, "Forecasting future energy production using hybrid artificial neural network and arima model," vol. 4004Graduate Theses, Dissertations, and Problem Reports, Morgantown, West Virginia, 2018.

[24] A. Ladanu, S. Akanmu, and J. Adeyemo, "Enhancing artificial neural network with multi-objective evolutionary algorithm for optimizing real time reservoir operations: a review," American Journal of Water Resources, vol. 8, no. 3, pp. 118127, 2020.

[25] N. Anuar, M. Khan, J. Pasupuleti, and A. Ramli, "Flood risk prediction for a hydropower system using artificial neural network," International Journal of Recent Technology and Engineering, vol. 8, no. 4, pp. 6177-6181, 2019.

[26] V. Sessa, E. Assoumou, and M. Bossy, Modeling the climate dependency of the run-of-river based hydro power generation using machine learning techniques: an application to French, Portuguese and Spanish cases. hal-02520128, 2020.

[27] P. Amarasinghe, N. Abeygunawardana, T. Jayasekara, E. Edirisinghe, and S. Abeygunawardane, "Ensemble models for solar power forecasting-a weather classification approach," AIMS Energy, vol. 8, no. 2, pp. 252-271, 2020.

[28] S. Karunathilake and H. Nagahamulla, "Artificial neural networks for daily electricity demand prediction of Sri Lanka," in Proceedings of the International Conference on Advances in ICT for Emerging Regions (ICTer), pp. 128-133, IEEE, Colombo, Sri Lanka, September 2017.

[29] C. Gunasekara, "Modelling and simulation of temperature variations of bearings in a hydropower generation unit," M.S. thesis, Sweden: Department of Energy Technology, Royal Institute of Technology, Stockholm, Sweden, 2011.

[30] E. Udayakumara and U. Gunawardena, "Reducinng siltation and Increasing hydropower generation from the rantambe reservoir, Sri Lanka. Kathmandu," South Asian Network for Development and Environmental Economics (SANDEE), vol. 113, no. 16, pp. 1-20, 2016.

[31] S. Chandrasekara, V. Prasanna, and H.-H. Kwon, "Monitoring water resources over the Kotmale reservoir in Sri Lanka using ENSO phases," Advances in Meteorology, vol. 2017, Article ID 4025964, 9 pages, 2017.

[32] N. Imbulana, S. Gunawardana, S. Shrestha, and A. Datta, "Projections of extreme precipitation events under climate change scenarios in Mahaweli river basin of Sri Lanka," Current Science, vol. 114, no. 7, pp. 1495-1509, 2018.

[33] A. Perera and U. Rathnayake, "Impact of climate variability on hydropower generation in an un-gauged catchment: Erathna run-of-the-river hydropower plant, Sri Lanka," Applied Water Science, vol. 9, no. 57, 2019.

[34] B. Khaniya, I. Jayanayaka, P. Jayasanka, and U. Rathnayake, "Rainfall trend analysis in Uma Oya basin, Sri Lanka, and future water scarcity problems in perspective of climate variability," Advances in Meteorology, vol. 2019, Article ID 3636158, 10 pages, 2019.

[35] M. Jakob Themeßl, A. Gobiet, and A. Leuprecht, "Empiricalstatistical downscaling and error correction of daily precipitation from regional climate models," International Journal of Climatology, vol. 31, no. 10, pp. 1530-1544, 2010.

[36] W. Cabos, D. V. Sein, A. Durán-Quesada et al., "Dynamical downscaling of historical climate over CORDEX central America domain with a regionally coupled atmosphere-ocean model," Climate Dynamics, vol. 52, no. 7-8, pp. 4305-4328, 2019.

[37] S. K. Dubey and D. Sharma, "Assessment of climate change impact on yield of major crops in the Banas River Basin, India," Science of The Total Environment, vol. 635, pp. 10-19, 2018.

[38] D. Jacob, B. J. J. M. Van Den Hurk, U. Andrae et al., "A comprehensive model inter-comparison study investigating the water budget during the BALTEX-PIDCAP period," Meteorology and Atmospheric Physics, vol. 77, no. 1-4, pp. 19-43, 2001.

[39] V. P. Pandey, S. Dhaubanjar, L. Bharati, and B. R. Thapa, "Hydrological response of Chamelia watershed in Mahakali basin to climate change," Science of the Total Environment, vol. 650 , pp. $365-383,2019$.

[40] S. A. Thasneem, N. Chithra, and S. Thampi, "Analysis of extreme precipitation and its variability under climate change in a river basin," Natural Hazards, vol. 98, no. 2, pp. 1169-1190, 2019.

[41] IPCC Climate Change, "Synthesis report. 2014. fifth assessment report of the intergovernmental panel on climate change," in Intergovernmental Panel on Climate Change, R. K. Pachauri and L. A. Meyer, Eds., pp. 1-151, Geneva, Switzerland, 2014.

[42] H. Kawase, T. Nagashima, K. Sudo, and T. Nozawa, "Future changes in tropospheric ozone under representative concentration pathways (RCPs)," Geophysical Research Letters, vol. 38, no. 5, 2011.

[43] D. P. V. Vuuren, J. Edmonds, M. Kainuma et al., "The representative concentration pathways: an overview," Climatic Change, vol. 109, no. 1-2, p. 5, 2011.

[44] J. H. Christensen, F. Boberg, O. B. Christensen, and P. LucasPicher, "On the need for bias correction of regional climate change projections of temperature and precipitation," Geophysical Research Letters, vol. 35, no. 20, 2008.

[45] C. Piani, J. O. Haerter, and E. Coppola, "Statistical bias correction for daily precipitation in regional climate models over Europe," Theoretical and Applied Climatology, vol. 99, no. 1-2, pp. 187-192, 2010.

[46] C. Teutschbein and J. Seibert, "Bias correction of regional climate model simulations for hydrological climate-change impact studies: review and evaluation of different methods," Journal of Hydrology, vol. 456-457, pp. 12-29, 2012.

[47] G. Lenderink, A. Buishand, and W. Van Deursen, "Estimates of future discharges of the river Rhine using two scenario 
methodologies: direct versus delta approach," Hydrology and Earth System Sciences, vol. 11, no. 3, pp. 1145-1159, 2007.

[48] U. Ghimire, G. Srinivasan, and A. Agarwal, "Assessment of rainfall bias correction techniques for improved hydrological simulation," International Journal of Climatology, vol. 39, no. 4, pp. 2386-2399, 2018.

[49] T. Lafon, S. Dadson, G. Buys, and C. Prudhomme, "Bias correction of daily precipitation simulated by a regional climate model: a comparison of methods," International Journal of Climatology, vol. 33, no. 6, pp. 1367-1381, 2013.

[50] M. Luo, T. Liu, F. Meng et al., "Comparing bias correction methods used in downscaling precipitation and temperature from regional climate models: a case study from the Kaidu river basin in Western China," Water, vol. 10, no. 8, p. 1046, 2018.

[51] R. Mahmood, S. Jia, N. K. Tripathi, and S. Shrestha, "Precipitation extended linear scaling method for correcting GCM precipitation and its evaluation and implication in the transboundary Jhelum river basin," Atmosphere, vol. 9, no. 5, p. 160, 2018.

[52] E. P. N. Udayakumara, R. P. Shrestha, L. Samarakoon, and D. Schmidt-Vogt, "Mitigating soil erosion through farm-level adoption of soil and water conservation measures in Samanalawewa Watershed, Sri Lanka," Acta Agriculturae Scandinavica, Section B-Soil \& Plant Science, vol. 62, no. 3, pp. 273-285, 2012.

[53] D. T. Udagedara, C. T. Oguchi, and J. K. Gunatilake, "Evaluation of geomechanical and geochemical properties in weathered metamorphic rocks in tropical environment: a case study from Samanalawewa hydropower project, Sri Lanka," Geosciences Journal, vol. 21, no. 3, pp. 441-452, 2017.

[54] E. P. N. Udayakumara and U. A. D. P. Gunawardena, "Costbenefit analysis of Samanalawewa hydroelectric project in Sri Lanka: an ex post analysis," Earth Systems and Environment, vol. 2, no. 2, pp. 401-412, 2018.

[55] K. Laksiri, J. Gunathilake, and Y. Iwao, "A case study of the Samanalawewa reservoir on the Walawe river in an area of Karst in Sri Lanka," in Proceedings of Tenth Multidisciplinary Conference Sinkholes and the Engineering and Environmental Impacts of Karst (GSP 144), San Antonio, TX, USA, September 2005.

[56] D. Wijesinghe, "Optimization of hydro-power potential of Samanalawewa project," Engineer: Journal of the Institution of Engineers, Sri Lanka, vol. 39, no. 1, p. 27, 2006.

[57] M. Pathiraja and W. Wijayapala, "Optimization of the usage of Samanalawewa water resource for power generation," in Proceedings of the 2016 Electrical Engineering Conference (EECon), Colombo, Sri Lanka, December 2016.

[58] B. D. Kristen and W. L. Lee, "Artificial neural networks for the management researcher: the state of the art, department of organizational leadership and strategy, Marriott school of management Brigham Young University Provo," UT 84602, 2003.

[59] U. R. Alo, S. I. Ele, and H. F. Nweke, “A conceptual framework for network traffic control and monitoring using artificial neural networks," Journal of Theoretical and Applied Information Technology, vol. 97, no. 22, pp. 3396-3412, 2019.

[60] T. Chaipimonplin, "Comparison learning algorithms for artificial neural network model for flood forecasting, Chiang Mai, Thailand," in Proceedings of the 22nd International Congress on Modelling and Simulation (MODSIM 2017), pp. 472-479, Hobart, Australia, December 2017.

[61] P. Chopra, R. K. Sharma, and M. Kumar, "Artificial neural networks for the prediction of compressive strength of concrete," International Journal of Applied Sciences \& Engineering, vol. 13, no. 3, pp. 187-204, 2015.

[62] A. Perera, U. S. Rathnayake, and H. M. Azamathulla, "Comparison of different artificial neural network (ANN) training algorithms to predict atmospheric temperature in Tabuk, Saudi Arabia, MAUSAM," Quarterly Journal of Meteorology, Hydrology, and Geophysics, vol. 71, no. 2, pp. 233-244, 2020.

[63] L. Zhou and X. Yang, "Training algorithm performance for image classification by neural networks," Photogrammetric Engineering \& Remote Sensing, vol. 76, no. 8, pp. 945-951, 2010.

[64] D. Baskaran, A. Sinharoy, T. Paul, K. Pakshirajan, and R. Rajamanickam, "Performance evaluation and neural network modeling of trichloroethylene removal using a continuously operated two-phase partitioning bioreactor," Environmental Technology \& Innovation, vol. 17, Article ID 100568, 2020.

[65] R. Celikel, "ANN based angle tracking technique for shaft resolver," Measurement, vol. 148, Article ID 106910, 2019.

[66] W. Han, L. Nan, M. Su, Y. Chen, R. Li, and X. Zhang, "Research on the prediction method of centrifugal pump performance based on a double hidden layer BP neural network," Energies, vol. 12, no. 14, p. 2709, 2019.

[67] M. Cai, M. Koopialipoor, D. Armaghani, and B. Thai Pham, "Evaluating slope deformation of earth dams due to earthquake shaking using MARS and GMDH techniques," Applied Sciences, vol. 10, no. 4, p. 1486, 2020.

[68] M. Koopialipoor, E. Ghaleini, H. Tootoonchi, D. Armaghani, M. Haghighi, and A. Hedayat, "Developing a new intelligent technique to predict overbreak in tunnels using an artificial bee colony-based ANN," Environmental Earth Sciences, vol. 78, no. 5, 2019.

[69] L. Sun, M. Koopialipoor, D. Armaghani, R. Tarinejad, and M. Tahir, "Applying a meta-heuristic algorithm to predict and optimize compressive strength of concrete samples," Engineering with Computers, 2019.

[70] D. Tang, B. Gordan, M. Koopialipoor et al., "Seepage analysis in short embankments using developing a metaheuristic method based on governing equations," Applied Sciences, vol. 10 , no. 5, p. 1761, 2020.

[71] G. Foody, "Impacts of sample design for validation data on the accuracy of feedforward neural network classification," Applied Sciences, vol. 7, no. 9, p. 888, 2017.

[72] Japan International Cooperation Agency (JICA), Samanalawewa Hydroelectric Power Project (I) (II) (III) and Samanalawewa Hydroelectric Project (Reservoir Remedial Works), Japan Water Agency, Colombo, Sri Lanka, 2006.

[73] H. S. Somatilake, K. A. U. S. Imbulana, P. Droogers, and I. W. Makin, "Water for energy," in Proceedings of the World Water Assessment Programme Sri Lanka Case Study, Ruhuna basins: Proceedings of a Workshop Held at Koggala Beach Hotel, Sri Lanka, International Water Management Institute, Colombo, Sri Lanka, pp. 129-141, April 2002. 